\title{
Design and performance analysis of a crowbar-less high voltage power supply based on PSM technique
}

\author{
S K THAKUR*, S K KUMARI and YASHWANT KUMAR \\ Variable Energy Cyclotron Centre, HBNI, 1/AF Bidhan Nagar, Kolkata 700064, India \\ e-mail: thakur@vecc.gov.in
}

MS received 20 June 2017; revised 15 November 2017; accepted 6 December 2017; published online 3 July 2018

\begin{abstract}
A high voltage power supply (HVPS) of rating $-40 \mathrm{kV}, 5 \mathrm{~A}$ is designed and developed based on pulse step modulation (PSM) technique for inductive output tube based RF amplifier. The commercial availability of such power supplies are very limited and that to at a very high cost. In future also, we shall need several PSM based HVPS of various ratings, so in-house development of a high voltage power supply is important to reduce the cost to less than half and also for easy maintenance. The present development is aimed to utilise a modern technique meeting all the important criteria, i.e., solid state based modular construction, crowbar-less design, reliable operation, voltage regulation with higher efficiency, fast response and most importantly easy to service. This paper deals with the design and development of HVPS rated at $-40 \mathrm{kV}, 5 \mathrm{~A}$ by using DSP TMS320F28335 as the main controller along with algorithms for the control system, interlocks and protections, test results, etc.
\end{abstract}

Keywords. High voltage; power supply; RF amplifier; PSM; crowbar protection.

\section{Introduction}

In a conventional high voltage power supply, the regulation is achieved by using a series tube operated in linear mode or by input variac or by SCR based phase angle controller. In such methods, there are disadvantages in terms of more power loss, lower efficiency, slow response, high stored energy, etc. This would result into implementation of an efficient crowbar protection system which is a very critical system for the protection of RF amplifier tubes [1] against internal arc faults. So, a latest technique based on pulse step modulation (PSM) technique [2-5] is adopted to develop the high voltage power supply. PSM based high voltage power supply consists of several switched type power supply modules (SPMs) and the output voltage is obtained by modulating their pulse widths and phase delay time. This results into very low ripple voltage at higher frequency which ultimately requires very small filter capacitor and thus no need of a special crowbar protection system. Other advantages are modular design, lesser EMI, less harmonics content, high efficiency [6, 7].

The high voltage power supply (HVPS) consists of two numbers of multi-secondary resin cast, air cooled transformers, each having 30 secondaries. Each secondary voltage is $580 \mathrm{~V}_{\mathrm{L}-\mathrm{L}}, 3$-phase and feeding power to 60 numbers of SPMs individually. Solid state based SPM uses an IGBT in series as a buck converter with a typical peak

*For correspondence voltage of $780 \mathrm{~V}$. The operation involves switching-on the required number of SPMs till a set value of output voltage is arrived. The output voltage setting and regulation is accomplished by pulse width modulation (PWM) of 2 SPMs with variable dc voltage. A DSP based control system is developed in order to ensure the trouble free operation of the power supply as well as option for future upgrade without much change in hardware.

\section{System descriptions}

In this section, description of the various components of the high voltage power supply along with multi-secondary transformers and switched power modules are given in details.

\subsection{Scheme of HVPS}

The cathode of IOT needs a well-regulated dc high voltage power supply with low ripple and low stored energy. For further improvement of its performance, some other features are also considered in design such as low noise, lower input current harmonics, improved power factor, higher efficiency, etc. In order to meet all the criterions mentioned above, the pulse step modulation (PSM) based power supply is considered to be the most suitable technique. The HVPS mainly consists of two multi-secondary resin cast 
transformers, switched power modules (SPMs), circuitbreaker, high voltage switch, DSP based control system, etc. as shown in the schematic diagram in figure 1. The photograph of HVPS is shown in figure 2 where all the 60 nos. of SPMs and other accessories are housed on glass epoxy structure and two resin cast multi-secondary transformers in rear side.

The detailed specifications of HVPS is listed in table 1.

\subsection{Multi-secondary transformers}

Two resin-cast transformers, each having 30 secondaries, are used at primary voltage rating $415 \mathrm{~V}, 3$-phase, $50 \mathrm{~Hz}$. Each secondary is rated at $580 \mathrm{~V}_{\mathrm{L}-\mathrm{L}}$, 3-phase, star connected feeding power to respective SPM. The primary of one transformers is star and other is delta connected, whereas all the secondary windings are star-connected to obtain 12-pulse rectification feature to reduce harmonics content in input current and low ripple voltage at ripple frequency $600 \mathrm{~Hz}$. The transformer's secondary 30 output coils on each limb which are kept at equal separation from each other. To provide high voltage insulation, these are then resin casted after vacuum impregnation to avoid any moisture or dirt. The insulation between two consecutive coils is maintained at $5 \mathrm{kV}$ whereas the insulation level of secondary coils with respect to primary coil as well as core is maintained at $80 \mathrm{kV}$. The stray capacitances $\mathrm{C}_{\mathrm{SP}}$ between primary to secondary windings and $\mathrm{C}_{\mathrm{SS}}$ between secondary windings are the key parameters and kept smaller for better results [8, 9]. The photograph of resin cast transformer mounted in a cabinet is shown in figure 3 . For the efficient cooling, two fans are connected on the top of the cabinet.

\subsection{Switched power modules (SPMs)}

The HVPS contains total 60 SPMs and each SPM gets power from individual 3-phase secondary at $580 \mathrm{~V}_{\mathrm{L}-\mathrm{L}}$ from multi-secondary transformers, as shown in figure 4. Each SPM is a buck converter which consists of a soft start feature by using contactors, 3-phase full wave bridge rectifier, filter capacitor, free-wheeling diode, IGBT (SKM200GAL173D), snubbers, varistors, LEM current sensor and a control board. Each module uses an inductor at output terminal to limit the surge current. The typical switching frequency of SPM is $5 \mathrm{kHz}$.

Each module provides typically $780 \mathrm{~V}$ at output when IGBT Q1 is turned ON. The output voltage is at zero voltage when IGBT Q1 is turned-off and freewheeling diode bypasses the module by providing a bypass current path for others. In case of short circuit condition, the series IGBT Q1 is turned off and IGBT Q2 is turned on for faster discharge. The control electronics is designed to interface for communication with the main controller through optical fibres and allows the switching of IGBT from local or remote mode. The series connection of all 60 modules leads to a relatively high complexity of high voltage cable and

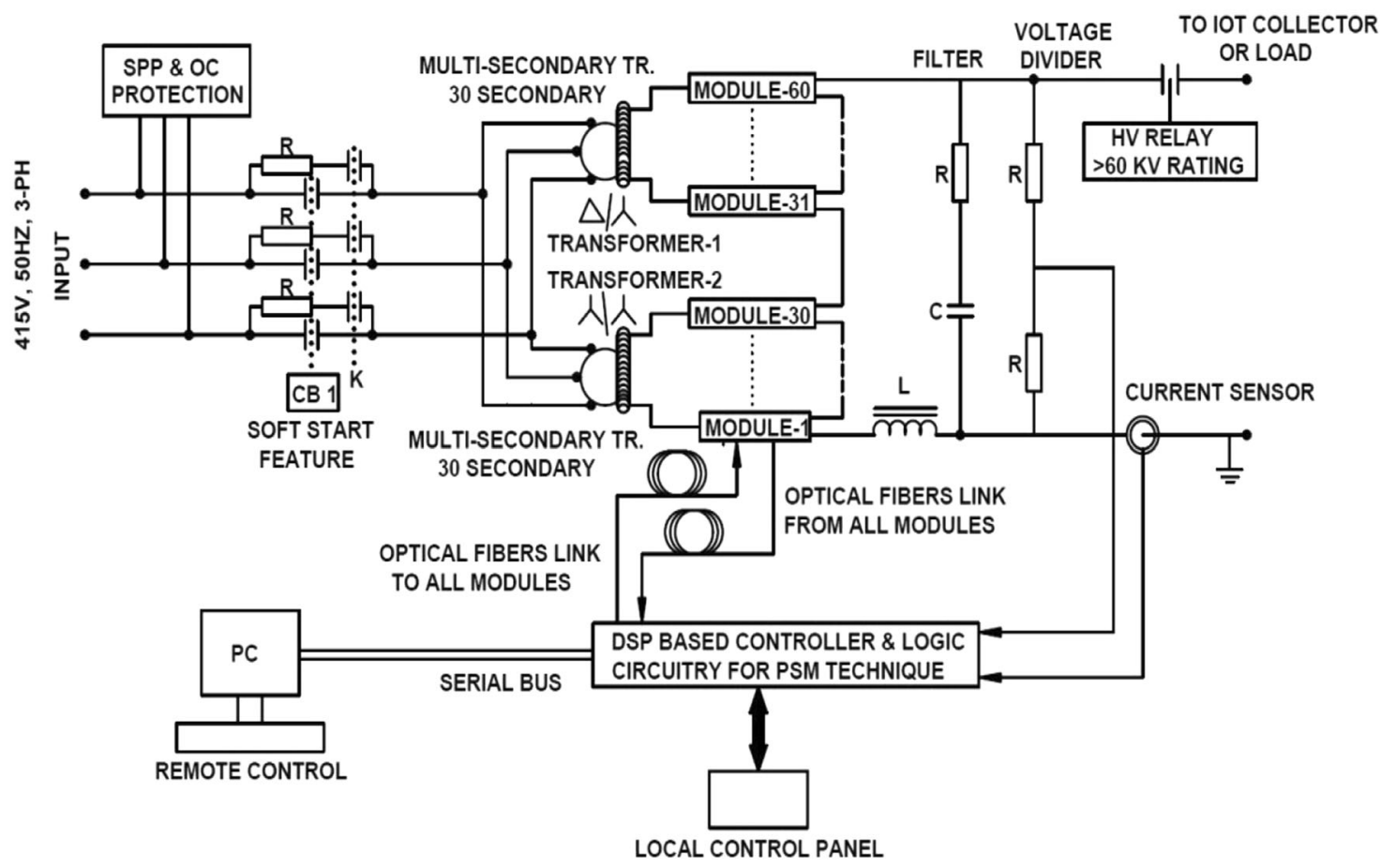

Figure 1. Schematic diagram of HVPS rated at $-40 \mathrm{kV}, 5 \mathrm{~A}$. 


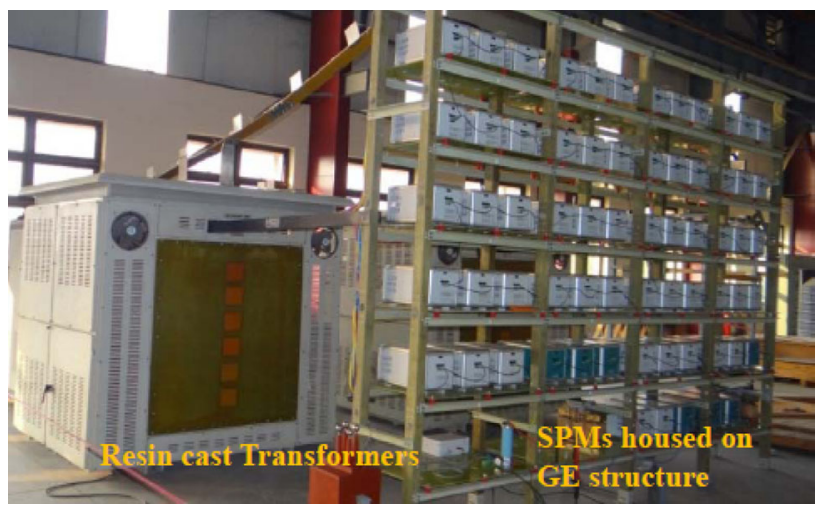

Figure 2. Photograph of HVPS showing all 60 SPMs and two resin-cast transformers rear side.

Table 1. Specifications of HVPS based on IOT requirement.

\begin{tabular}{|c|c|c|}
\hline $\begin{array}{l}\text { Sl. } \\
\text { no. }\end{array}$ & Parameters & Values \\
\hline 1 & Input voltage & $415 \mathrm{~V} \mathrm{AC} \pm 10 \%, 3$ phase, $50 \mathrm{~Hz}$ \\
\hline 2 & Max. output voltage & 0 to $-40 \mathrm{kV} \mathrm{DC}$ \\
\hline 3 & Output current & $4 \mathrm{~A},(\max$ rating $5 \mathrm{~A})$ \\
\hline 4 & Ripple voltage & $<0.5 \%$ \\
\hline 5 & Load regulation & $<0.5 \%$ (from $10 \%$ to $90 \%$ of load) \\
\hline 6 & Line regulation & $\begin{array}{c}<0.5 \%( \pm 10 \% \text { of input } \mathrm{AC} \\
\text { variation })\end{array}$ \\
\hline 7 & Input PF & $\sim 0.95$ \\
\hline 8 & $\begin{array}{c}\text { Output voltage rise } \\
\text { time }\end{array}$ & $<250 \mathrm{~ms}$ (from 0 to $V \max$ ) \\
\hline 9 & $\begin{array}{l}\text { Shutdown time during } \\
\text { fault condition }\end{array}$ & $<20 \mu \mathrm{s}$ \\
\hline 10 & Stored energy & $<25 \mathrm{~J}$ \\
\hline 11 & $\begin{array}{l}\text { Typical overall } \\
\text { efficiency }\end{array}$ & Better than $90 \%$ \\
\hline 12 & Remote interface & $\begin{array}{c}\text { RS-232/485 based communication } \\
\text { with PC and Graphical User } \\
\text { Interface (GUI) for operation } \\
\text { and monitoring }\end{array}$ \\
\hline 13 & Output interlocks & $\begin{array}{l}\text { Over voltage, over current, short } \\
\text { circuit due to internal arching, } \\
\text { module failure, IGBT over temp }\end{array}$ \\
\hline 14 & $\begin{array}{l}\text { Mains input side } \\
\text { interlocks }\end{array}$ & $\begin{array}{c}\text { Under voltage, over voltage, over } \\
\text { current, phase fail }\end{array}$ \\
\hline
\end{tabular}

optical fibre connections. Two SPMs are made vernier modules utilising PWM switching voltage regulator used for the regulation. These SPM's output voltage varies typically from zero to $780 \mathrm{~V}$ depending upon the duty cycle. The regulation system is developed as per the algorithm mentioned later where the controller decides the number of switch-on modules in addition to the vernier SPMs.

During operation with a proper modulation strategy, the output ripple frequency seen by the load equals to switching frequency multiplied by number of modules. This feature allows the higher ripple frequency at output even if the switching frequency is less. The control cards of SPM takes care of an effective protection in case of any internal faults and keep the status of health of modules informed to the main controller through optical fibre communication.

\subsection{Supervisory control and monitoring}

The supervisory control and monitoring system for all the power supplies including HVPS is developed in-house by using PLCs and is programmed using Simatic manager software provided by Siemens. Siemens S7-300 PLC is used which handles all the fields I/Os. It takes care of all safety interlocks like over voltage, overcurrent, water flow, air flow, etc. along with the start-up interlocks. All other power supplies kept at high voltage deck are controlled by Siemens distributed I/O modules (ET-200) with ethernet. An ethernet to optical and optical to ethernet channel is used to navigate the control signals from high voltage deck to PLC. A GUI is made to control the HVPS from PC as shown in figure 5 along with control and monitoring of parameters of other systems also.

\section{Control architecture of HVPS}

In this section, the detailed control architecture of PSM based HVPS will be discussed apart from the mathematical calculations, the main flow diagram that will ensure closed loop feedback by using TMS320F28335 DSP controller.

\subsection{Working principle of PSM}

Figure 6 shows $N$ number of DC modules, each consists of a DC source $V s$, a solid-state switch $S_{i}$ and a freewheeling diode $D_{i}$, where $i$ denotes the number of SPM modules from 1 to $N$. The total output voltage across load is the sum of the respective output voltages of each SPM. The output voltage equals $V s$ for a closed switch $S$ and zero for an opened switch $S$ for any SPM. In coarse step modulation (CSM) control, the controller switched on $n$ SPMs (where $n \leq N$ ) in order to get output voltage $n V_{s}$. The problem arising with this approach is that we can get only integer value of $V s$ at the output. But sometime fine steps are to be added and for this, we have added two SPMs for fine-tuning. The difference between required output voltage and CSM voltage is added with PWM-pulses, which are generated just by switching on additional steps.

Simulation result of four SPMs operated in PSM approach is shown in figure 7 . Each module has equal duty cycle with a fixed phase shift to ensure equal loading. It can be seen that the output voltage reaches $4 V s$ with peak to peak ripple voltage equal to one SPM voltage $(V s)$ at a 


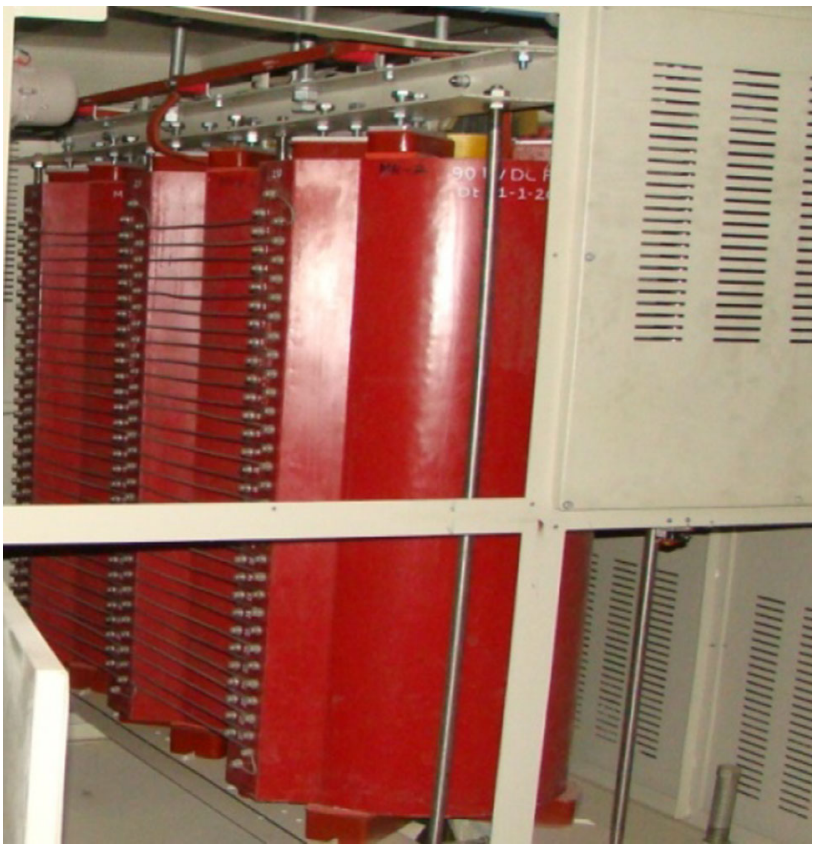

Figure 3. Actual photograph of a resin cast multi-secondary transformer, having overall dimension $1700 \mathrm{~mm} \times 650 \mathrm{~mm}$, $\mathrm{H}=1600 \mathrm{~mm}$

ripple frequency four times SPM switching frequency. Thus, it would require 16 times less filter capacitor value that could inherently reduce the stored energy and therefore easing the need of additional crowbar protection system. At full voltage, the number of modules will be further increased resulting in very low stored energy.
Assuming total output voltage $V_{o}$, delay time $T_{d}$ between consecutive SPMs, the frequency $f_{o}$ and modified duty cycle $D_{o}$ can be calculated as follows [10-12]:

$$
\begin{gathered}
T_{d}=\frac{T}{N} \\
V_{o}=N V_{s} \frac{T_{o n}}{T} \\
f_{o}=N f_{s} \\
D_{o}=\left(T_{o n}-m T_{d}\right) N f_{s}
\end{gathered}
$$

where $f_{s}$ is the switching frequency of one SPM and $N$ is the number of working SPMs. $V_{s}, T_{o n}, T, T_{d}$ and $f_{s}$ are input voltage, switch on time, time period, delay time and switching frequency, respectively. $N$ is the total number of switch-on SPM and $m$ is the integer part of $T_{o n} / T_{d}$. So the output voltage and efficient frequency can be adjusted by changing $V_{s}, T_{o n}$ and $f_{s}$.

Figure 7 shows the simulated output voltage of 4 SPMs with switching frequency $f_{s}=5 \mathrm{kHz}, V_{s}=1000 \mathrm{~V}$, duty cycle $80 \%$. As control signal of the PSM is based on stage rotation, therefore the second switch will turn on $T / 4$ time later than the first one, the third will turn on $T / 4$ later than second one and forth is turned on $T / 4$ later on than third one and so on. The output waveform $\left(V_{\text {out }}\right)$ shows that ripple voltage (peak to peak) is equal to one module voltage $V_{s}$ and ripple frequency equals to four times $f_{s}$. From Eq. (4) duty cycle at the output stage is $20 \%$. Thus the output waveform resulting from PSM modulation gives more advantages. For $N=3$, keeping other parameter constant

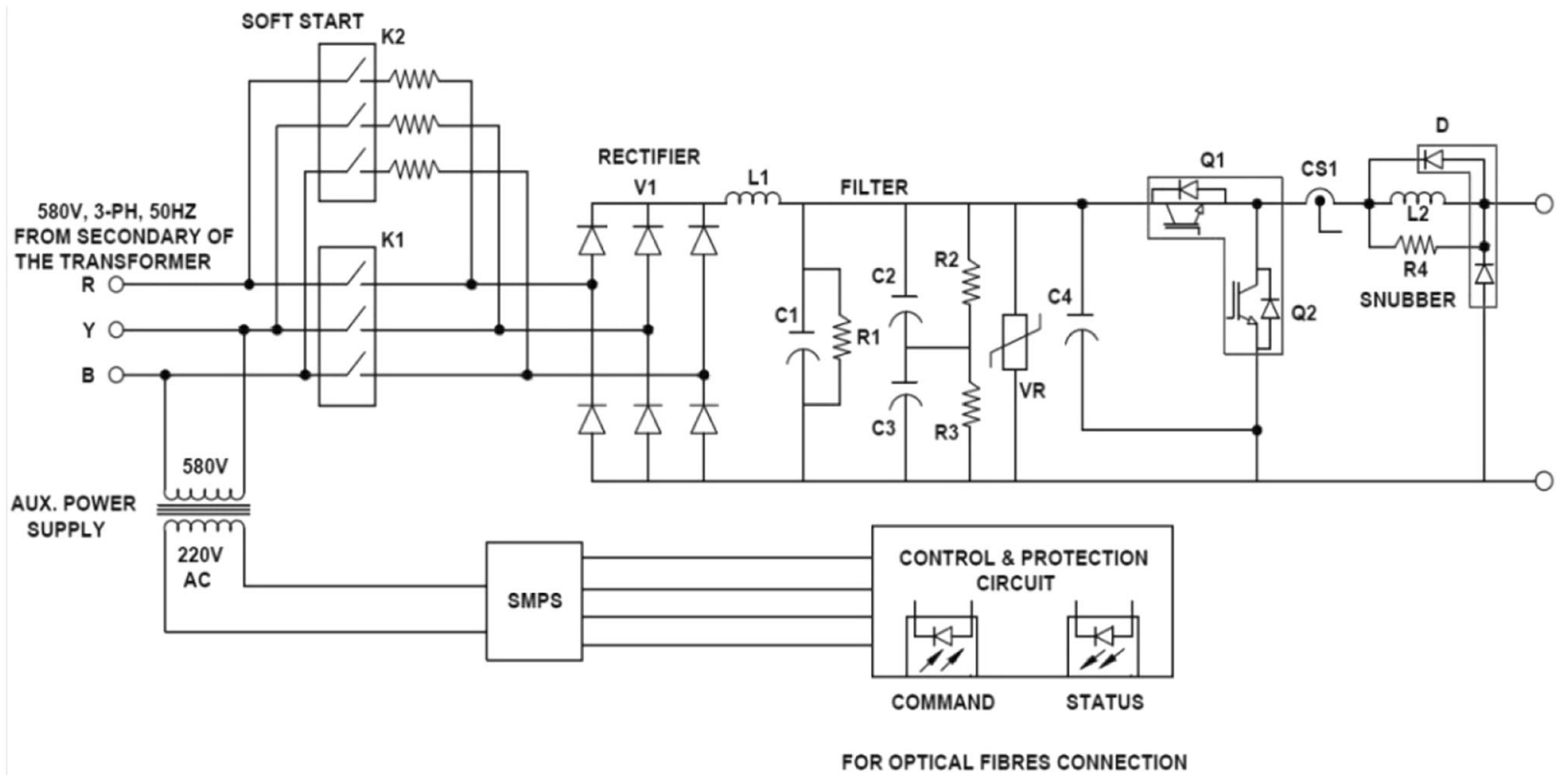

Figure 4. Schematic diagram of a SPM module. 


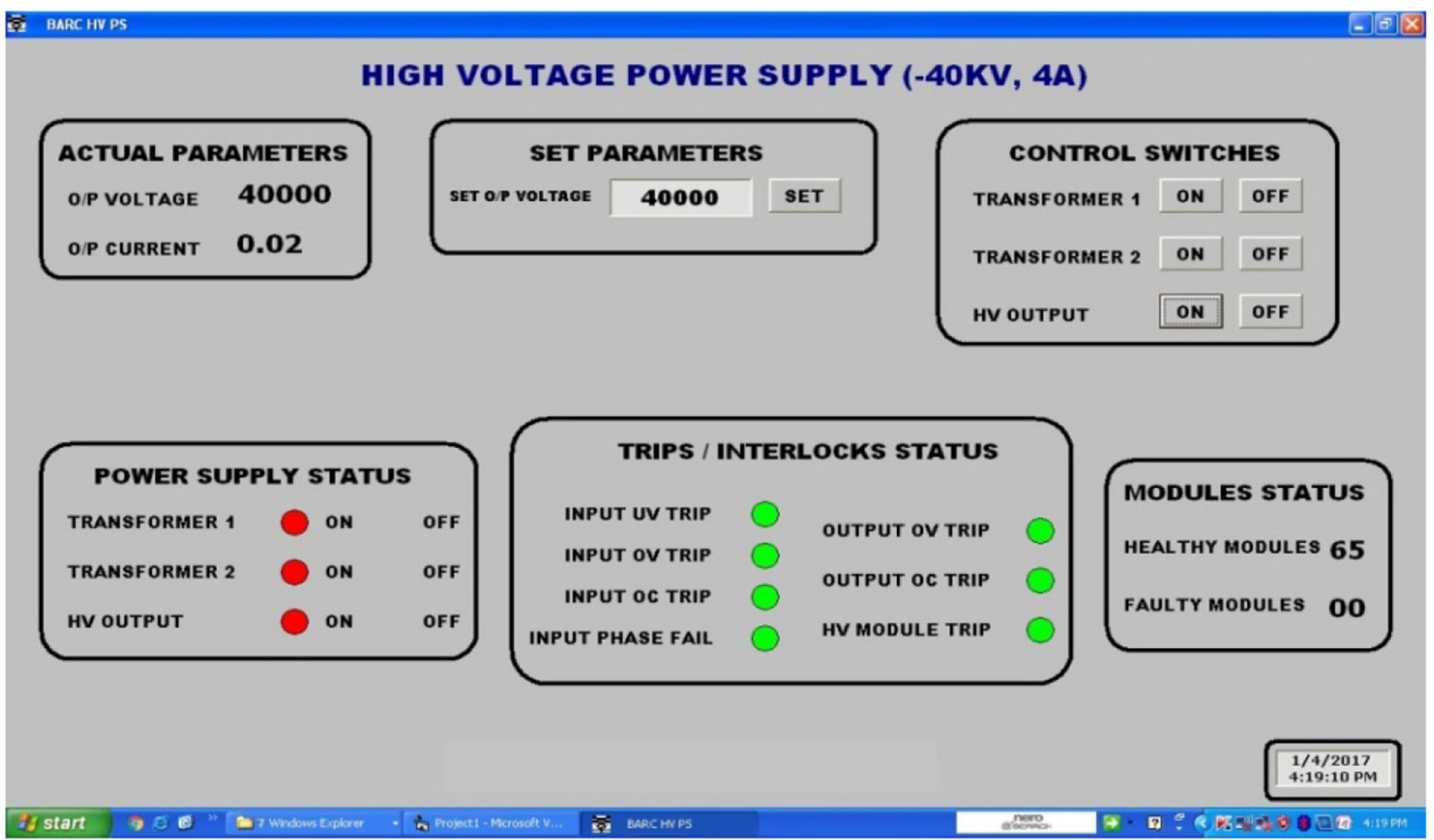

Figure 5. HVPS control and monitor GUI.

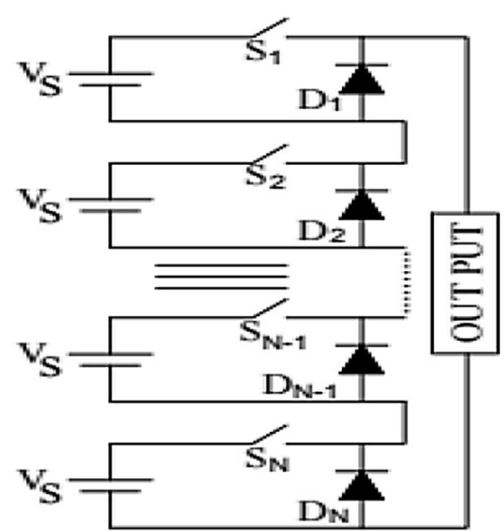

Figure 6. Working principle of PSM based HVPS.

$T_{d}=\mathrm{T} / 3$, ripple voltage at output stage is equal to one module voltage, duty cycle at output stage $D_{o}=28 \%$. Similarly, for $N=8$, Duty cycle $D_{o}=40 \%$ and $T_{d}=\mathrm{T} / 8$.

Duty cycle of output stage depends on $m$ ie, integer part of $T_{o n} / T_{d}$. If $T_{o n}$ is integer multiple of $T_{d}, D_{o}=0$ output is absolutely ripple free. For $N=4, T_{d}=50 \mu \mathrm{s}$, there are four possible $T_{o n}(50 \mu s, 100 \mu s, 150 \mu s, 200 \mu s)$ for which $D_{o}=0$ so, the filter capacitor requirement is almost nil. Hence, in case of four modules there are four duty cycle points where output is ripple free. Similarly, in $N$ number of power modules there are $N$ duty cycle points where output contain almost no ripple voltage [9]. This strategy avoids or minimizes the output filter capacitance requirement resulting very low stored energy.

\subsection{Closed loop control program}

HVPS consists of total 60 SPMs out of which 58 SPMs having fixed duty cycle and 2 SPMs having variable duty cycle incorporating PWM at same switching frequency at $5 \mathrm{kHz}$ and is used for output voltage regulation. During the load disturbances, the difference between required output voltage and Coarse Step Modulation voltage is added with PWM-pulses and gives the output voltage within $200 \mathrm{~V}$ of set voltage. In order to realize the precise timing control of the PSM modules, Texas Instrument floating point Digital Signal Processor TMS320F28335 is used as the core controller to generate pulses for switch-on and switch-off of IGBT for each module. The DSP controller is used because of its advantages, i.e., low cost, embedded floating-point unit, high clock speed, high resolution, on-chip ADCs, high performance PWM unit, etc.

ADC input channels are used to receive feedback voltage and current signals. Four to sixteen line multiplexer (74HC154) is used to turn ON/OFF 16 SPMs and is controlled using digital input output pins of DSP, as shown in figure 8. Two SPM modules are controlled using PWM 


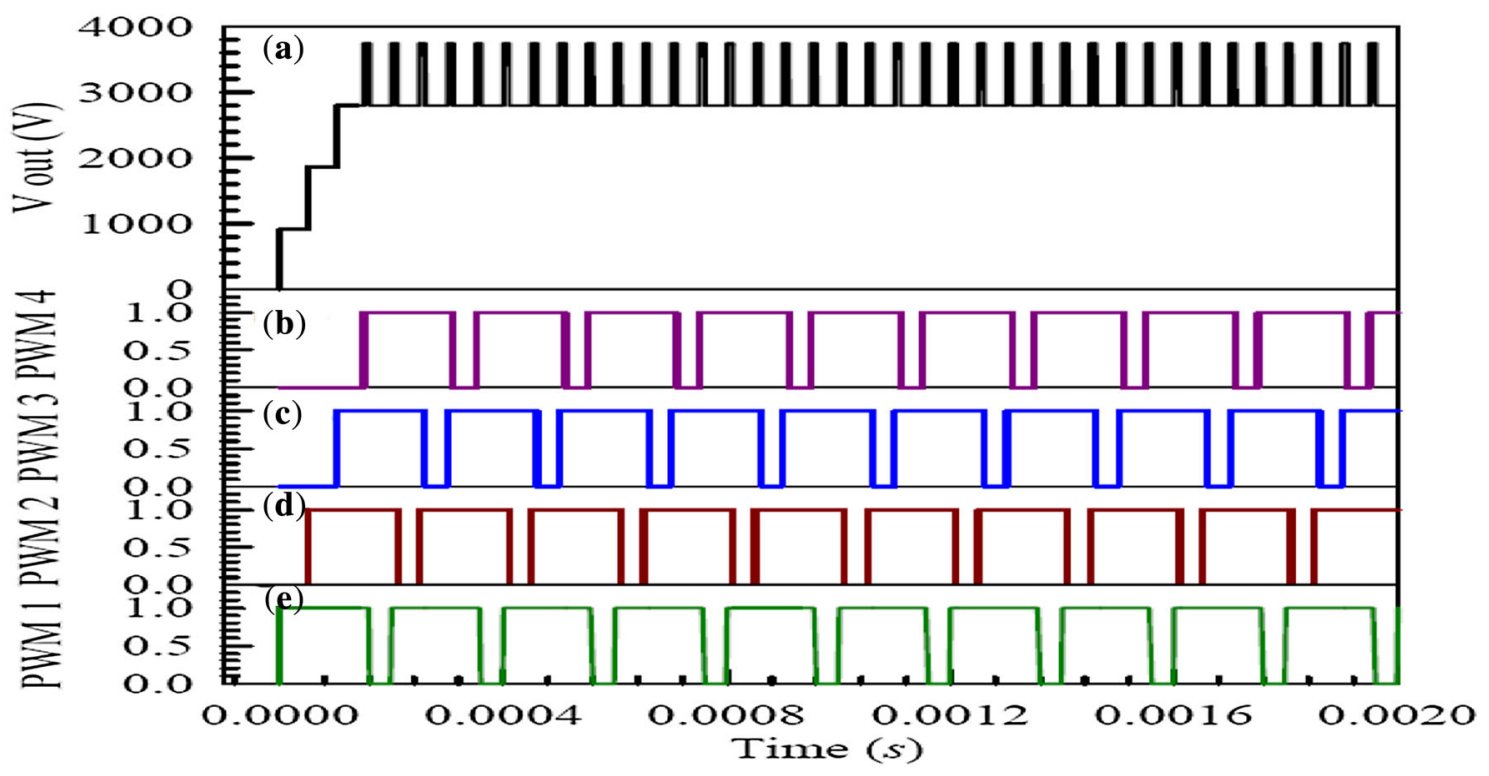

Figure 7. Output voltage waveform with shifted PWM for $N=4$.

pins of DSP which has been implemented for fine tuning of the output voltage and also for the regulation and controls. For rest of the SPMs, digital output is used to control switch-on and switch-off according to the required set voltage. The controller can turn off all the SPMs quickly in case of any faults occur such as over current and crowbar, etc. Individual SPM is protected against internal faults, i.e., IGBT short circuit, over temperature, overcurrent, etc. The power supply can be either operated remotely using graphical user interface (GUI) or from local panel.

The DSP is used as an independent master controller without slave controller which is a simpler design and a cost effective solution. The DSP based controller has extra advantages like flexibility, accuracy, less effect of noise, reconfigurable without much change in hardware, etc. The only drawback is slow speed which requires few more ms

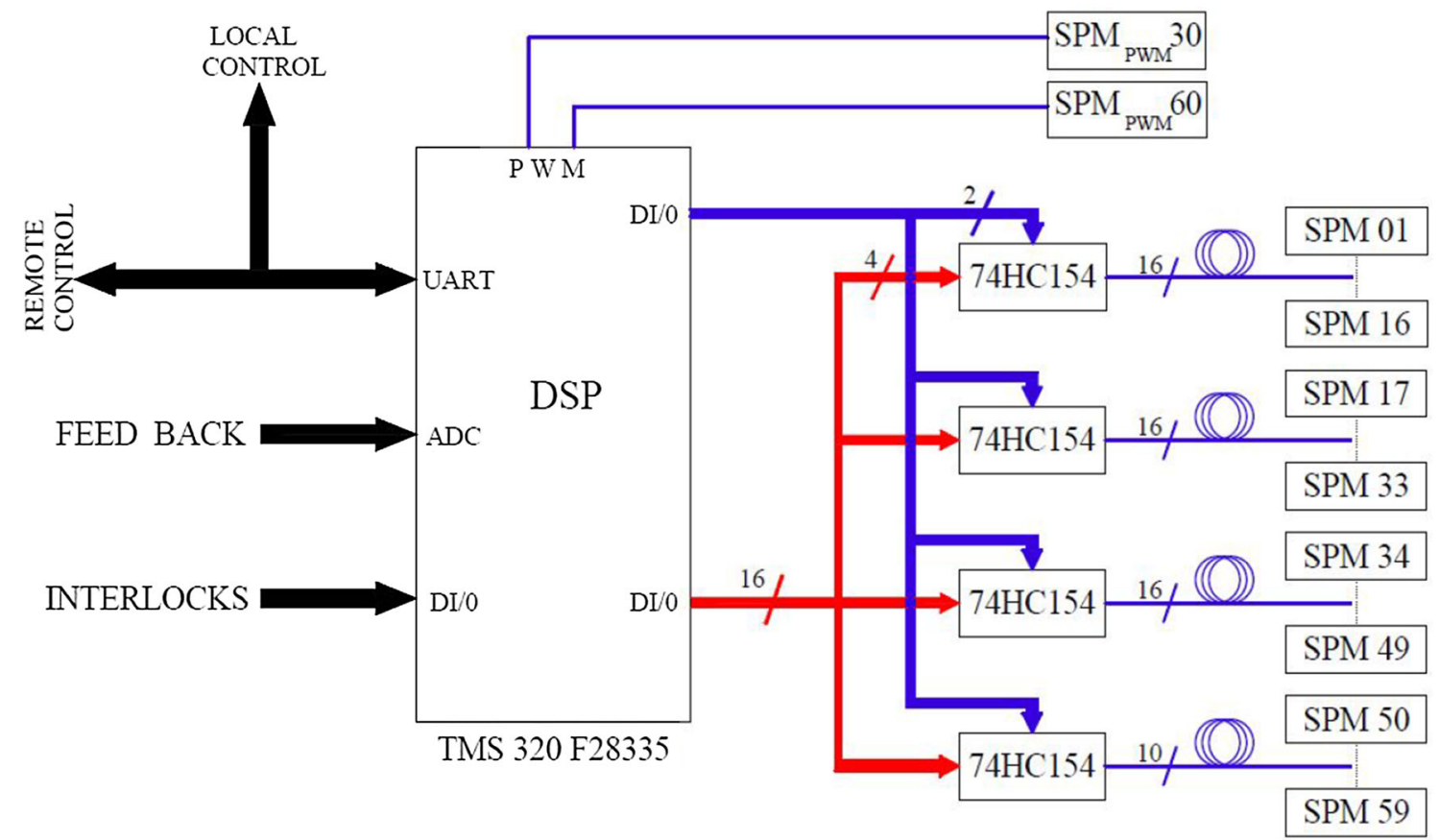

Figure 8. Block diagram of DSP based HVPS control architecture. 


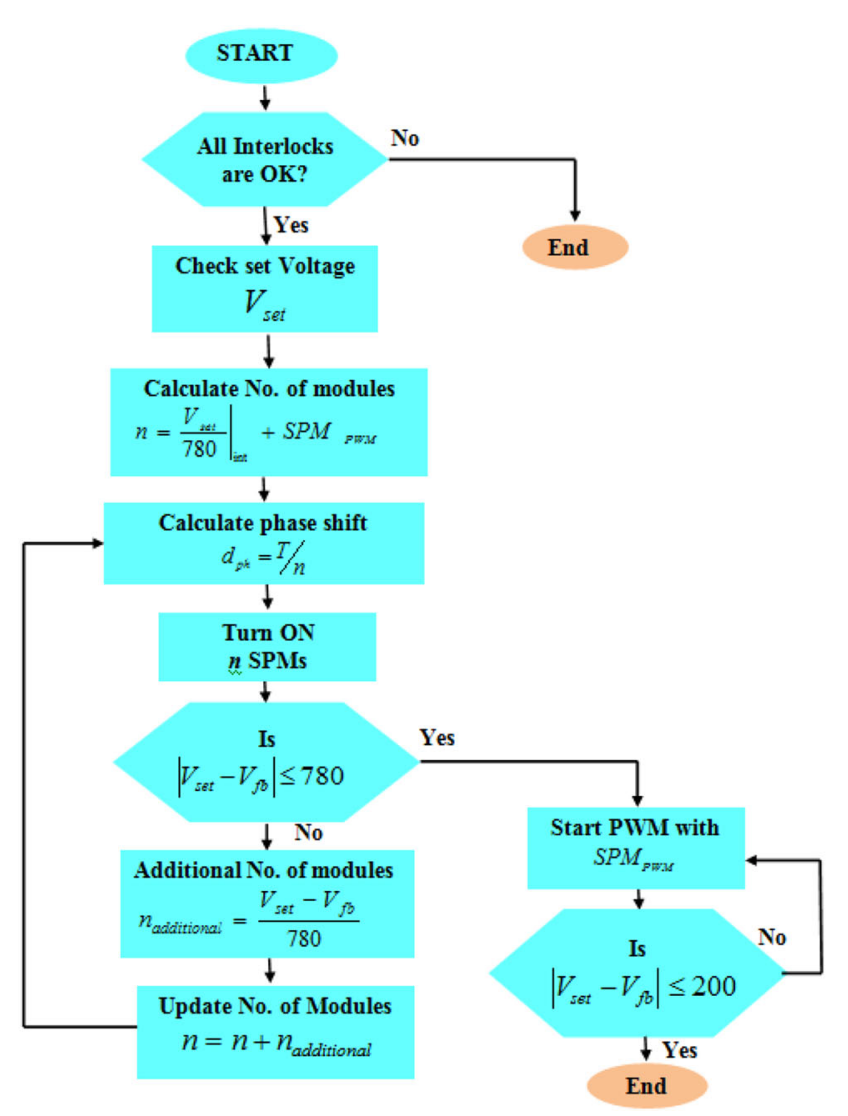

Figure 9. Flow diagram of control architecture.

time to achieve the desired set value, which is not very serious issue in our case.

The detailed control architecture is based on the flow diagram as shown in figure 9. Flow diagram starts checking all the interlocks and then it checks the set voltage $V_{\text {set }}$. Since the duty cycle is fixed for a specific number of modules, phase shift $\left(T_{d}\right)$ can be calculated. The number of
SPMs to turn on is given by $\mathrm{n}=V_{\text {set }} / 780$. The fraction part of $V_{\text {set }} / 780 \mathrm{~V}$ is controlled by two SPMs operating as a buck converter.

\section{Test results of HVPS}

Both the resin cast transformers were tested at factory. Results of all major tests, such as turns ratio test, polarity test, magnetic balance test, IR test, Insulation test at $80 \mathrm{kV}$ (between all secondary shorted to HV with respect to primary coils and screen and core at ground) and DVDF test (double voltage at double frequency) were found to be satisfactory and overall performance of the transformers was found to be as per the requirements.

A test stand was made for functionality test and full load test of each SPM at rated input voltage. Heat run test was performed on randomly selected $25 \%$ of modules at full current and maximum temperature of power components was measured to be less than $73^{\circ} \mathrm{C}$ at an ambient temperature of $25^{\circ} \mathrm{C}$ which is within the safe limit. After assembly, the HVPS was tested at full voltage at $-40 \mathrm{kV} \mathrm{dc}$ and rise time and fall time are recorded up to load current at 3 A, i.e., $120 \mathrm{~kW}$ power for short time due to availability of load. We have used Tektronix make oscilloscope of model TPS2024B for measurements and recorded the waveforms of output voltage in positive polarity by selecting the "INVERT" mode for the convenience. In the voltage divider network, we used $400 \mathrm{M} \Omega$ in series with $200 \mathrm{~K} \Omega$ to measure the HV in the ratio of 2000:1.

Figure 10(a) shows that the rise time and $(b)$ shows the fall time of output voltage which is around $10-15 \mu$ s at no load, respectively. The resistive load of $40 \mathrm{~kW}$ is available which is used to test the power supply at higher current for short time. The Line as well as load regulation of HVPS was tested at resistive load and found to be better than $0.5 \%$. The overcurrent protection at different current level
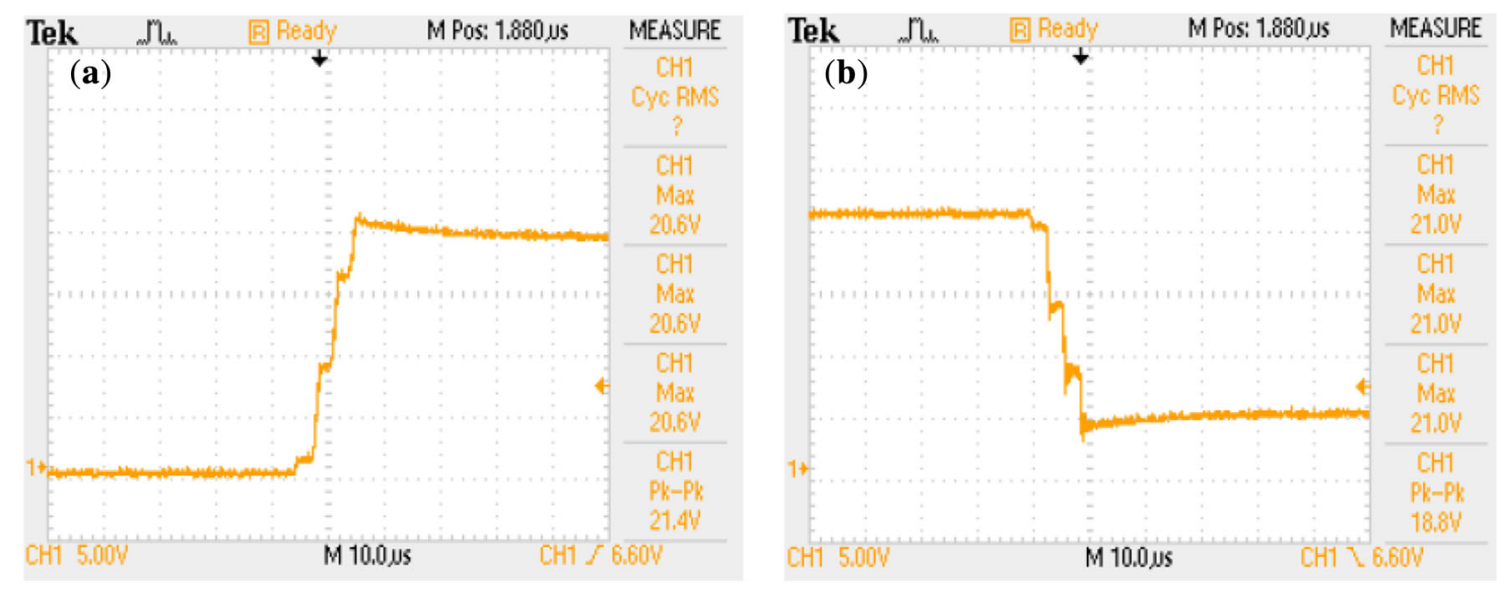

Figure 10. Rise time and fall time of output voltage $(10 \mathrm{kV} / \mathrm{div})$ at $-40 \mathrm{kV}$ at no load with voltage divider in the ratio $2000: 1$. 

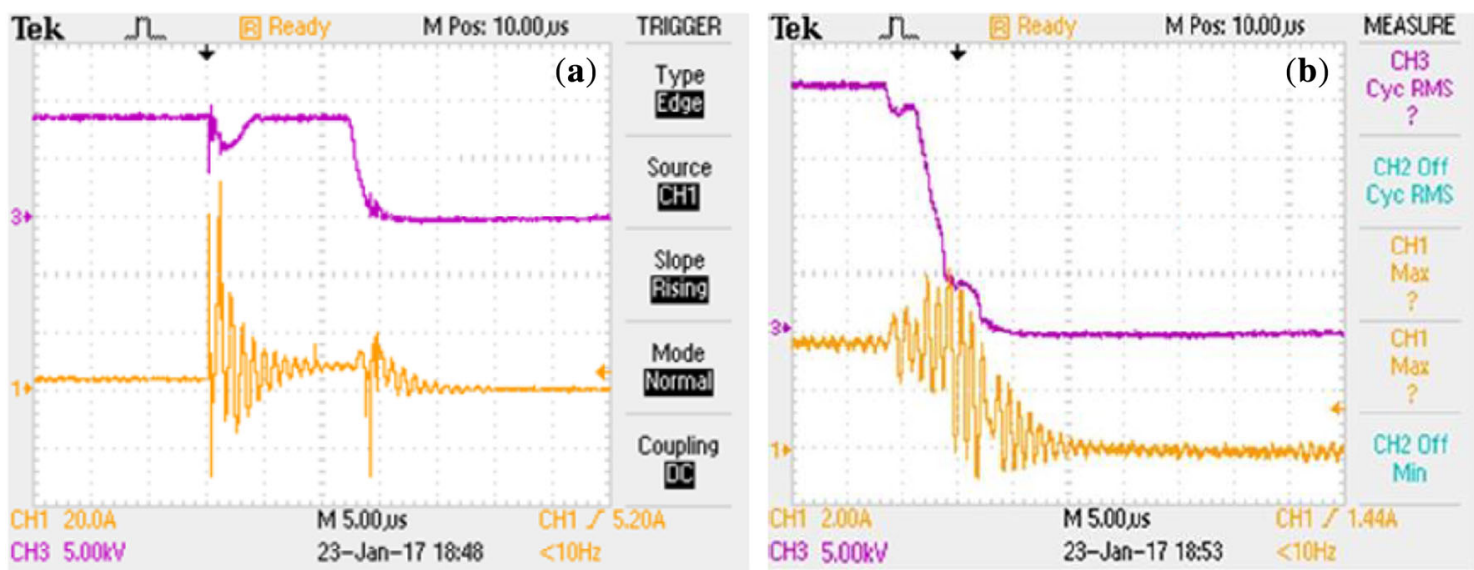

Figure 11. Crowbar test (a) at $-25 \mathrm{kV}(\mathrm{CH} 3$ :voltage $15 \mathrm{kV} / \mathrm{div}$ at voltage divider ratio 3000:1) $\mathrm{CH} 1: \mathrm{current}=2.5 \mathrm{~A}$ at $20 \mathrm{~A} / \mathrm{div})$, (b) at $-40 \mathrm{kV}$ (CH3:voltage $10 \mathrm{kV} / \mathrm{div}$ which with divider ratio 2000:1 by using voltage divider; $\mathrm{CH} 1: \mathrm{current}=4 \mathrm{~A}$ at $2 \mathrm{~A} / \mathrm{div}$ ).

settings from 3.0 A to $6.0 \mathrm{~A}$ was performed successfully at lower voltage.

The power supply as well as RF amplifier tube must be protected against crowbar or short-circuit caused by internal arcing. To demonstrate low energy dump ( $<25$ Joules) to the load during a fault, wire bun test was performed at load resistance $10 \mathrm{k} \Omega$. For this purpose, a crowbar test setup was connected across the output terminals. The test setup consists of a high voltage relay in series with a piece of a thin $33 \mathrm{SWG}$ copper wire of $140 \mathrm{~mm}$ long suitable for $25 \mathrm{~J}$ of energy transfer [1].

The crowbar tests of HVPS are performed at various voltages from -10 to $-40 \mathrm{kV}$. The crowbar test results performed at -25 and $-40 \mathrm{kV}$ is shown in figure 11 . The short circuit current was measured using a LEM CT and a current probe. The output terminals are made short-circuited by using a thin copper wire by closing a high voltage relay. The fault condition was detected by the controller and subsequently all the IGBTs get switched-off within $15 \mu$ s without burning of thin copper wire. The tests were repeated and similar results were found. As shown in the figure 11(b), during short circuit, the current ringing is more that was corrected by using suitable filter capacitor and snubber in the output.

\section{Summary and conclusion}

The HVPS has been developed, installed and tested with available resistive load up to $120 \mathrm{~kW}$ power level for a short time. Due to unavailability of services of IOT, the actual load installation took some more time. Individually, all the modules were tested at full load and found to be compliant and meeting all the specifications. The HVPS delivers excellent operating performances with inherent redundancy, faster dynamic response, low stored energy and improved efficiency. Overall, HVPS testing was carried out up to $-40 \mathrm{kV}$ at $3 \mathrm{~A}$ current (not exceeding $120 \mathrm{~kW}$ ) for a short time and full current at $25 \mathrm{kV}$. This is due to the available resistive load. After the IOT installation and commissioning along with water cooling and other services, the RF testing was started.

\section{Acknowledgements}

The authors would like to thank all the staff members of PE and MC and RF sections, Variable Energy Cyclotron Centre at Kolkata for their help and support during the development and testing of the power supplies.

\section{References}

[1] Thakur S K 2016 Design and performance of high voltage power supply with crowbar protection for 3- $\Phi$ high power RF amplifier system of cyclotron. J. Instrum. (JINST) 11: T07004. https://doi.org/10.1088/1748-0221/11/07/t07004

[2] Alex J and Schminke W 1995 Fast switching modular high voltage DC/AC power supplies for RF amplifiers and other applications. In: Proceedings of 16th IEEE/NPSS SOFE, vol. 2, pp. 936-939

[3] Schminke W 1985 High-power pulse-step modulator for $500 \mathrm{~kW}$ short-wave and $600 \mathrm{~kW}$ medium-wave transmitters. Brown Boveri Rev. 73: 235-240

[4] Schminke W 1988 The development of plasma-heating equipment and classical high-power broadcast transmitter technology. In: Proceedings on 15th SOFT, Utrecht

[5] Zhang J, HaoXu, Wei W and Huang Y 2106 The design of PSM-based ECRH power supply control system. J. Power Energy Eng. 4: 91-102

[6] Pan S M, Fu P, Yang L, Hu C D 2011 The control system of the $100 \mathrm{kV}$ HVPS for NBI. In: IEEE/NPSS 24th Proceedings of Symposium on Fusion Engineering SP3-34

[7] Tomljenovic N and Schminke W 1992 Solid state dc power supplies for gyrotron and NBI sources. In: Proceedings of Symposium on Fusion Technology 
[8] Singh N P, Baruah U K, Patel P J, Mattoo S K and NBI Team 2005 Studies on the behaviour of multi-secondary transformers used for regulated HV power supplies. Fusion Eng. Des. 75-79: 127-133

[9] Tripathi V, Singh N P, Gupta L N, Kapil Oza, Paresh Patel and Baruah U K 2008 Development of cast resin multi-secondary $1600 \mathrm{kVA}$ transformer for regulated high voltage power supply-a prototype. In: 23rd National Symposium on Plasma Science \& Technology (PLASMA-2008)

[10] Patel P, Sharma P K, Sumod C B, Dipal Thakkar, Laxmi N Gupta, Patel V B, Vijay Vadher, Ambulkar K K, Dalakoti S, Rajan Babu, Virani C G, Parmar P R, Thakur A L and Ujjwal
K Barua 2014 Regulated high-voltage power supply (RHVPS): integration, operation and test results with LHCD system of SST-1. IEEE Trans. Plasma Sci. 42(3): 651-655

[11] Lieying Y, Wang Y, Mao X, Wang Y and Li Q 2014 A fully digital controller of high-voltage power supply for ECRH system on HL-2A. In: 2011 IEEE/NPSS 24th Symposium on Fusion Engineering

[12] Mao X H, Yao L Y, Wang Y Q, Wang Y L, Li Q, Zhang M and Xuan W M 2014 A pulse step modulator high voltage power supply for auxiliary heating system on the HL-2A Tokamal. IEEE Trans. Plasma Sci. 42(5): 1425-1429 